\title{
Sources of Nominal Exchange Rate Fluctuations in South Africa
}

Ashok Bhundia and Jan Gottschalk 


\title{
IMF Working Paper
}

\author{
African and Policy Development and Review Departments \\ Sources of Nominal Exchange Rate Fluctuations in South Africa \\ Prepared by Ashok Bhundia and Jan Gottschalk ${ }^{1}$ \\ Authorized for distribution by Doris C. Ross and Martin Gilman
}

December 2003

\begin{abstract}
This Working Paper should not be reported as representing views of the IMF. The views expressed in this Working Paper are those of the author(s) and do not necessarily represent those of the IMF or IMF policy. Working Papers describe research in progress by the author(s) and are published to elicit comments and to further debate.
\end{abstract}

This paper investigates the sources of fluctuations in the rand-U.S. dollar exchange rate in 2001 and 2002 using an empirical exchange rate model which identifies aggregate supply, aggregate demand, and nominal disturbances as possible sources for exchange rate fluctuations. According to our results, nominal disturbances explain by far most of the rand depreciation in the final quarter of 2001. The fact that the nominal effective exchange rate also depreciated sharply suggests the nominal disturbances were domestically generated. From a preliminary examination of the relative movements in policy interest rates in South Africa and the United States, along with growth rates in both narrow and broad monetary aggregates in South Africa, it is difficult to isolate the underlying cause of the nominal disturbances in 2001 and 2002. Clearly, the task remains a challenging one with the empirical tools available.

JEL Classification Numbers: E3,F41

Keywords: Nominal exchange rate, real disturbances, nominal disturbances, structural VAR Authors’ E-Mail Addresses: abhundia@imf.org and jgottschalk@,imf.org

\footnotetext{
${ }^{1}$ The authors would like to express their appreciation for comments received from staff in the African Department, and the South African team in particular, at the IMF.
} 


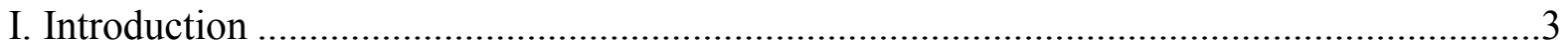

II. The Myburgh Commission Report...........................................................................

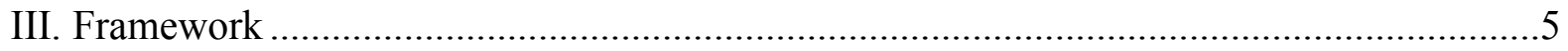

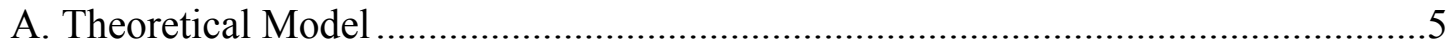

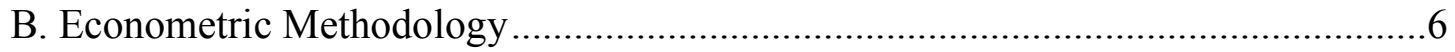

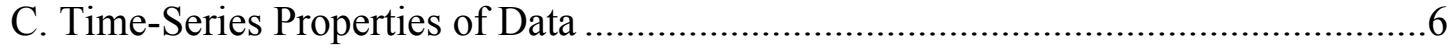

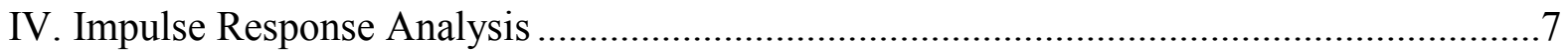

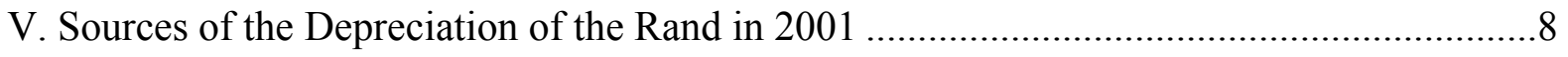

VI. Identifying the Nominal Disturbances Causing the Depreciation .................................. 10

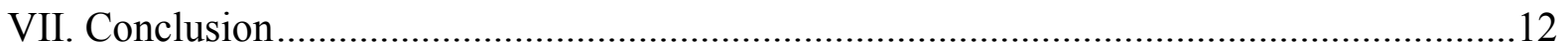

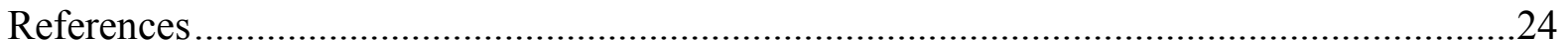

Figures

1. Impulse Response Functions for the Aggregate Supply Shock ........................................13

2. Impulse Response Functions for the Real Demand Shock ............................................14

3. Impulse Response Functions for the Nominal Shock ..................................................15

4. Actual and Projected Annual Change in the Nominal Exchange Rate..............................16

5. Historical Decomposition of the Nominal Exchange Rate ............................................17

6. Nominal Effective Exchange Rates for the Rand and the U.S. Dollar ............................... 18

7. Relative Monetary Policy Stance in South Africa: Discount Rate and Treasury Bill

Rate Differential vis-à-vis the United States. ...........................................................19

8. Monetary Aggregates and the Rand Exchange Rate..................................................20

Table

1. Various Decomposition of the Nominal Exchange Rate ...............................................21

Appendix

Appendix Figure

A1. Time-Series Plot

Appendix Tables

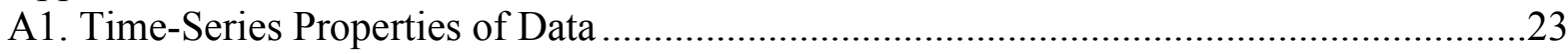

A2. Misspecification Tests............................................................................................23 


\section{INTRODUCTION}

The South African rand depreciated sharply against the U.S. dollar in the last four months of 2001 - by 42 percent between September and December - after a steady decline earlier in the year. The unexpected depreciation in the final months of 2001 led to widespread public concern, and the South African Reserve Bank was faced with the prospect of a significant increase in inflation. Some policymakers also voiced their beliefs that the marked acceleration in the rate of depreciation was not justified by economic fundamentals and may have been caused by speculators taking short positions against the rand. The President of South Africa responded to events by setting up the Myburgh Commission of Inquiry, mandating it to investigate the causes of the depreciation in 2001, including whether there was any evidence that capital control regulations had been violated. The Myburgh Commission released its final report on August 2002 which pointed to several macroeconomic factors behind the depreciation. Chief among them were; (i) a continued slowdown in global economic activity, (ii) contagion from events in Argentina, (iii) a worsening in the current account balance in the fourth quarter of 2001, and (iv) complete shift from a surplus in the financial account of the balance of payments in the third quarter to a deficit in the fourth quarter as explanations for the rand depreciation up to October 2001. The Commission, however, was unable to explain the acceleration of the depreciation in the final quarter. In particular, it did not find definitive evidence to suggest that currency speculation had driven down the rand.

In this paper, we revisit the causes of the depreciation and use an empirical exchange rate model to analyze the fluctuations in the South African rand against the U.S. dollar. Our analysis is based on a framework proposed in Clarida and Gali (1994), which combines a theoretical exchange rate model with an empirical structural vector autoregression methodology (SVAR). In the theoretical model, exchange rate fluctuations are due to aggregate supply, aggregate demand, or nominal disturbances. The first two types of disturbance consist of supply, and demand-side effects on the real economy. The slowdown in the global economy and the deterioration in the current account balance identified by the Myburgh Commission as partial explanations for the depreciation are two examples of such shocks. Nominal disturbances affect nominal variables like prices or money balances. Examples of nominal disturbances are moneysupply-side factors such as monetary policy actions, or money-demand-side factors such as financial market developments, including contagion from other financial markets.

The Clarida and Gali (1994) framework attributes fluctuations in the exchange rate to the three types of disturbance identified by the theoretical exchange rate model, making it possible to investigate which type of disturbance contributed most to the depreciation in 2001. Based on this analysis, we find that the depreciation in the final quarter of 2001 was driven predominantly by nominal disturbances which most likely originated in South Africa. A preliminary examination of movements in policy interest rates in South Africa vis-à-vis the United States suggests that monetary policy in South Africa was not the cause of these nominal disturbances, leaving developments in financial markets as a prime suspect. Since the theoretical model implies that nominal disturbances have no long-run effects on the real exchange rate, our finding suggests that the real depreciation will eventually be reversed (which is, indeed, occurring as this paper goes to print), even though the nominal depreciation may persist. Since it 
is the real exchange rate which matters for decisions to allocate resources between the tradable and nontradable sectors, the long-run macroeconomic implications of the depreciation episode are likely to be limited.

Before proceeding with the empirical analysis, we briefly outline in the following section the results of Myburgh Commission to provide some background on developments prior to the depreciation. The framework proposed by Clarida and Gali (1994) for exchange rate analysis has been frequently used in the literature, and therefore we will confine ourselves to providing only a brief outline of its main features in Section III. Next, in Section IV, we evaluate the empirical model by assessing whether the impulse response functions showing the exchange rate dynamics of the model are consistent with the predictions from our theoretical model. Having shown that our model yields plausible dynamics, we proceed in Section V to identify the causes of the large depreciation in 2001 and early 2002. In Section VI, we discuss the source of the nominal disturbances. In Section VII, we conclude with short discussions of the outlook on avenues for further research and the policy implications.

\section{The Myburgh COMMission RePORT}

The Myburgh Commission's final report concluded that several macroeconomic factors contributed to the rand depreciation in 2001. It points to a key factor as being the slowdown in global economic activity during this time period that weakened the rand in at least two waysby reduced foreign currency availability in the rand market and, by leading to reduced capital inflows to emerging markets, including South Africa. In addition, the Commission found financial market developments to have played an important role. The deepening crisis in Argentina led to a rise in global risk aversion toward emerging markets, and events in Zimbabwe amplified this trend. The Commission also pointed to the South African Reserve Bank's policy of nonintervention in the foreign exchange market (reflecting its objective to reduce its net open foreign position) as having contributed to the depreciation pressures by creating the impression that the rand was a one way bet.

However, since all these factors were present throughout most of 2001, it remains puzzling why the sharp depreciation established itself only in the final months of the year. The Commission points to adverse movements in the balance payments in the last quarter of 2001 as specific factors to explain the year-end depreciation. At that time, the current account went into deficit, while the financial account also moved into deficit. The Commission however, concedes that the acceleration in the rate of depreciation in this quarter nevertheless remains difficult to explain.

In the remainder of this paper, we are going to supplement the investigation of the Myburgh Commission with an empirical analysis that attributes the exchange rate fluctuations to three distinct types of disturbances. These disturbances can be thought of, in the words of Bernanke (1986), “as 'primitive' exogenous forces, not directly observed by the econometrician, which 
buffet the system and cause oscillations."2 According to this view, an observable event like a slowdown in global economic activity, for example, is a symptom of a disturbance buffeting the economic system, but is not identical with the unobservable disturbance itself. That is, the disturbances we seek to identify should be considered as the exogenous driving forces behind such events. Thus, our analysis does not aim to pinpoint specific events that led to the depreciation, but seeks to identify the primitive force most responsible for it. Even though this analysis does not deliver a 'smoking gun' in the form of a specific event that can be directly linked to the depreciation, it does help to narrow the area to look for such a piece of evidence.

\section{FRAMEWORK}

\section{A. Theoretical Model}

The Clarida and Gali (1994) model is a stochastic two-country version of the well-known Dornbusch (1976) model and captures the dynamics of relative output, the real exchange rate and relative prices. ${ }^{3}$ All variables are expressed in relative terms to capture the importance of foreign as well as domestically generated disturbances for exchange rate fluctuations.

The model is made up four equations an IS relationship: a money-market or LM relationship, an uncovered interest parity relationship and a relative price relationship. Clarida and Gali (1994) close the model by specifying random walk processes for three exogenous variables in the model. These are (i) an aggregate supply disturbance such as an increase in productivity; (ii) a real demand disturbance such as an increase in government spending, (iii) and a nominal disturbance. These three structural disturbances introduce stochastic dynamics into the behavior of the endogenous variables in the model.

The theoretical model has important implications for the long-run effects of the disturbances that will prove useful for the empirical application. Consistent with standard macroeconomic models with sticky prices, in the short run real demand disturbances and nominal disturbances have only a short-run impact on output and are neutral in the long-run. Hence, in this model only aggregate supply disturbances can have a permanent effect on the level of output. The real exchange rate is determined in the long run only by aggregate supply and real demand disturbances - that is, nominal disturbances have no long-run effects on the real exchange rate. In sum, this model yields three long-run restrictions: nominal disturbances have no long-run effects on output and the real exchange rate, and the long-run effect of a real demand disturbance on output is also restricted to zero.

\footnotetext{
${ }^{2}$ See Bernanke (1986), p. 52.

${ }^{3}$ See Lane (2001), Astley and Garratt (2000), and Funke (2000) for details of the model.
} 


\section{B. Econometric Methodology}

Following Clarida and Gali (1994), we estimate a three-variable VAR comprising relative output, relative prices and the real exchange rate. All variables are expressed in logarithms. The relative variables are expressed as South African variables vis-à-vis the United States, because we are interested in analyzing the source of fluctuations in the rand-U.S. dollar exchange rate. Therefore, the logarithm of the relative output variable is defined as the logarithm of real GDP in South Africa minus the logarithm of real GDP in the United States; the real exchange rate is the rand-U.S. dollar exchange rate adjusted for the relative price levels in South Africa and the United States; and the relative price variable is the logarithm of the price level in South Africa versus the logarithm of the price level in the United States.

The three structural disturbances are identified by imposing long-run restrictions on the reduced form residuals from the VAR using the empirical methodology proposed by Blanchard and Quah (1989). The three long-run restrictions are derived from the theoretical model discussed above. In essence, the empirical methodology imposes the long-run structure of the theoretical model on the empirical model. This has the effect of giving a structural interpretation to the residuals of the three equations in the empirical model, and these residuals are now interpreted as aggregate supply, real demand and nominal disturbances, respectively.

One major advantage of this methodology is that it does not impose constraints on the short-run dynamics of the empirical model. That is, the short-run effects of the structural disturbances on the variables in the model are not constrained, and by comparing the estimated short-run effects with our theoretical prior assumptions, we can judge whether the empirical model yields reasonable dynamics from a theoretical viewpoint. Due to the assumption of stick prices in the theoretical model, we expect both real demand and nominal disturbances to have short-run effects on output, even if the long-run effects are limited to zero. Moreover, we expect a nominal disturbance that leads to higher inflation to induce a transitory depreciation of the real exchange rate.

\section{Time-Series Properties of Data}

We restrict the sample period from the first quarter of 1985 until the second quarter of 2002 to avoid changes in the exchange rate regime in South Africa in earlier years from affecting our results. The time series for the relative variables we use in this paper are plotted in Figure 1A. The salient features of these variables are that output in South Africa was declining relative to the United States in the first half of the sample period, while prices in South Africa were rising faster than in the United States throughout the time period considered here, and the real exchange was depreciating since the early 1990s. The sharp depreciation of the real exchange rate at the end of 2001 is clearly visible. We also included a plot of the nominal exchange rate. Like the price variable, the nominal exchange rate shows an upward drift over time, 
representing a trend rate of depreciation. Since the nominal exchange rate is of central interest to us, below we also present the impulse response analysis for this variable. ${ }^{4}$

Before proceeding with the estimation, it is necessary to test for the degree of integration of the variables. Using standard augmented Dickey Fuller tests, all three variables were found to be I(1) as illustrated in Figure A $1{ }^{5}$ We also tested for cointegration between the variables. The Johansen rank test indicates the presence of one cointegration vector. Estimating the model with the rank restriction imposed shows a cointegration relationship between the relative output and price variables. However, the resulting cointegration vector displays signs of severe instability, and, hence, we proceed to estimate the VAR in first differences. Information criteria indicate that a lag length of one is sufficient to capture the information in the model, but we increase the lag length to three to obtain white noise residuals. ${ }^{6}$

\section{IMPULSE RESPONSE ANALYSIS}

In Figures 1 to 3 we plot the cumulative impulse responses showing the response of the output and price variable, real exchange rate, and nominal exchange rate to the aggregate supply disturbance, real demand disturbance and nominal disturbance, respectively. ${ }^{7}$ To facilitate comparison, all three disturbances are scaled so that they increase the output variable on impact by one percent. ${ }^{8}$ The figures show the response of the variables for the following 20 quarters.

In Figure 1, we show the response to the supply disturbance. The increase in output in South Africa relative to the United States is accompanied by a relative decline in the price level in South Africa. Since it is a key characteristic of a supply disturbance to drive output and prices in opposite directions, the response shown in Figure 1 is consistent with the predictions of our theoretical model. The real exchange rate initially appreciates slightly in response to the supply disturbance, but then a pronounced and persistent depreciation sets in, which is the long-run response predicted by Clarida and Gali's model. The nominal exchange rate response corresponds to the sum of the real exchange rate and relative price variable responses; hence, the nominal exchange rate also depreciates in the long run, but by less than the real exchange rate because of the negative price response.

${ }^{4}$ Even though this variable does not enter our empirical model directly, it can be constructed from the relative price variable and the real exchange rate variable.

${ }^{5}$ Results are shown in Table A1 in the Appendix.

${ }^{6}$ The results for several misspecification tests are shown in Table A2 in the Appendix.

${ }^{7}$ Since the variables are in first differences, we accumulate the impulse responses to obtain the response of level of each of the variables to the structural shocks in the model.

${ }^{8}$ That is, output in South Africa increases by 1 percent relative to output in the United States. 
In Figure 2, we plot the response to a positive real demand disturbance. In this case, there is an increase in output, an increase in the price level, and an appreciation of the real exchange rate. Both responses are predicted by our theoretical model. The nominal exchange rate also appreciates. In the long run, the output response is restricted to zero. The price and the exchange rate responses, on the other hand, turn out to be very persistent. This suggests that a demand disturbance typically leads to a long-lasting change in demand conditions - triggered, for example, by a sustained change in the fiscal policy stance.

The response to the nominal disturbance is shown in Figure 3. The output response lasts for about a year, and is accompanied by a large depreciation of the nominal and real exchange rate. In the long-run, both the output and the real exchange rate responses are restricted to zero. But the nominal disturbance is followed by a persistent increase in the price level, and, consequently, in the nominal exchange rate. It is noteworthy that the nominal exchange rate overshoots its long-run level considerably, which is consistent with the predictions of the familiar Dornbusch (1976) model.

The forecast error variance decomposition is another way to analyze the dynamics of our structural VAR model. This measure attributes the variance of the forecast error at different horizons to the structural disturbances in our model. This helps us to determine the relative importance of the disturbances for the fluctuations of the variables in our model. Since this paper focuses on the nominal exchange rate, we report in Table 1 the variance decomposition only for the rand-U.S. dollar exchange rate, which shows that in the short-run unexpected changes in the nominal exchange rate are almost entirely due to nominal disturbances. This is due to the large initial effect these disturbances have on the exchange rate relative to the other disturbances. At the one-year horizon, nominal disturbances still account for about 60 percent of the variance decomposition, but at the two-year horizon this share has declined to about onethird. At this horizon, real demand disturbances are the most important source of unexpected fluctuations in the nominal exchange rate. In the long run, the role of nominal disturbances is also superseded by aggregate supply disturbances.

\section{SOURCES OF THE DEPRECIATION OF THE RAND IN 2001}

We indicated in the introduction that the large depreciation of the rand in the final quarter of 2001 was largely unexpected. This can also be illustrated with the help of our empirical VAR model, since this type of model is often used for forecasting purposes. To abstract the results from high-frequency noise, it is useful to consider the annual change instead of the quarterly change in the exchange rate. ${ }^{9}$ In Figure 4, we plot for 2001 and 2002 the corresponding dynamic forecast together with the actual annual change in the nominal exchange rate. The resulting forecast error is shown as the shaded area. It is clear from Figure 4 that until the third quarter of

${ }^{9}$ The annual change refers to the change in the exchange rate over four quarters. 
2001 changes in the exchange rate were largely predictable, since the forecast error remains below 5 percent throughout this period. The following depreciation in the fourth quarter of 2001, however, results in a very large forecast error, which supports our earlier assertion that it was largely unexpected.

We now decompose the forecast error plotted in Figure 4 into the components attributable to the aggregate supply, real demand, and nominal disturbances, respectively. ${ }^{10}$ Technically speaking, this is called the historical decomposition of the forecast error. ${ }^{11}$

The historical decomposition technique is based on the following decomposition of the vector $X$,

$$
X_{t+j}=\sum_{s=0}^{j-1} C_{s} \varepsilon_{t+j-s}+\sum_{s=j}^{\infty} C_{s} \varepsilon_{t+j-s},
$$

where $X$ is a vector containing the three variables in our model (expressed in levels), $\varepsilon$ contains the three structural disturbances, and $C$ denotes the (accumulated) impulse response functions. This representation of our model shows that the variables in $X_{t+j}$ are composed of two types of terms. The term on the far right contains the information that is available at time $t$. Based on this information the expected $X_{t+j}$ can be computed, which is the so-called "base projection" of $X_{t+j} \cdot{ }^{12}$ The first term on the right hand side contains the effects of the "new" structural disturbances that hit the economy in the time period from $t+1$ to $t+j$. Since these disturbances are unexpected, this term can be interpreted as the forecast error of $X_{t+j}$ over a forecast horizon of $j$ periods. The historical decomposition is based on this part of the system, because it allows us to attribute the unexpected change in $X_{t+j}$ to individual structural disturbances buffeting the economy. In our case we set $j=4$, thereby obtaining a decomposition of the unexpected annual change in the variables in our model.

In Figure 5, we plot the corresponding historical decomposition for the time period 2001: Q1 until 2002: Q2. The solid line represents the total forecast error of the unexpected annual change in the nominal exchange rate, which is identical to the shaded area in Figure 4. The dotted lines in the three panels show the contribution to the forecast error of the aggregate supply

${ }^{10}$ More specifically, we decompose the forecast error resulting from a forecast horizon of four quarters; the latter corresponds to the forecast of the annual change of the exchange rate computed above

${ }^{11}$ For a discussion of the historical decomposition technique, see Fackler and MacMillin (1997).

12 The base projection contains also the effects of the deterministic part of the model. For simplicity, we have abstracted in the representation above from the deterministic terms. 
disturbance, real demand disturbance, and the nominal disturbance, respectively. The historical decomposition shows clearly that almost all of the unexpected depreciation in the fourth quarter of 2001 and the first quarter of 2002 is due to nominal disturbances. Since the impulse response analysis demonstrated that nominal disturbances have their strongest effect on the exchange rate on impact, the nominal disturbances that led to the strong depreciation in 2001: Q4 and 2002:

Q1 must have occurred in these two quarters. The impulse response analysis also shows that the effects of nominal disturbances on the exchange rate dissipate relatively quickly; after two quarters about half of the initial effect has dissipated. In fact, by the second quarter of 2002 the preceding depreciation has been already been partially reversed. In the long-run, our model implies that two-thirds of the initial depreciation of the nominal exchange rate will be reversed, and that there will be no long-run effects on the real exchange rate. Since it is the real exchange rate that matters for most economic decisions, this implies that the long-run economic consequences of the depreciation episode in 2001/2002 are likely to be limited.

\section{IDENTIFying The Nominal DisturbanCes CAUSING THE DePRECIATION}

The historical decomposition analysis shows that nominal disturbances explain almost all of the fluctuations in the rand seen in the second half of 2001 and the first quarter of 2002. This means that developments in the real sector of the economy, like the slowdown in global economic activity, are unlikely to be significant explanations for the sharp depreciation at year-end 2001 . This is consistent with the analysis of the Myburgh Commission, since the final report points out that the global economic slowdown had already begun in 2000 and had continued in 2001, which implies that the timing does not coincide with the depreciation of the South African rand at the end of the $2001 .{ }^{13}$ Our analysis suggests that we should be looking for nominal disturbances that explain the depreciation, especially during the latter half of 2001. Since our model is based on relative variables, this raises the possibility that the nominal disturbances could have originated either in the U.S. or the South African economy. Moreover, nominal disturbances could be due to monetary policy actions or they could result from disturbances in financial markets. In the remainder of this section, we try to narrow the source of the nominal disturbances further.

If the nominal disturbance originated in the U.S. economy, one would expect the U.S. dollar to have also appreciated against a broad range of currencies; conversely, if the nominal disturbance originated in South Africa, the rand would depreciate not only against the U.S. dollar but also against other currencies. In Figure 6, we plot the nominal effective exchange rate for both the U.S. dollar and the South African rand. It is apparent that during 2001 and the first half of 2002 the nominal effective exchange rate for the U.S. dollar remained

13 The Myburgh Commission however, observes that the global economic slowdown could have contributed to the depreciation of the Rand up to September 2001. This conclusion is supported by our historical decomposition analysis, since Figure 5 shows that adverse real demand shocks, which are consistent with a global economic slowdown, led to a depreciation in the third quarter of 2001. 
broadly constant, whereas the nominal effective exchange rate for the rand depreciated sharply. From this observation it follows that it was the rand that lost in value against other currencies, and not the U.S. dollar that gained in strength, indicating that the nominal disturbance originated in the South African economy.

One possible source of the nominal disturbance identified by our model would be an easing in the monetary policy stance of the South African Reserve Bank (SARB) relative to the United States, in which case lower interest rates or an acceleration in money supply in South Africa would have been a primary cause of the depreciation. We approach the question whether a change in the monetary policy stance in South Africa contributed to the depreciation in two ways. First, using Figure 7, we carry out a preliminary assessment of the relative monetary policy stance of the SARB s compared with the Federal Reserve using two short-term interest rates - the three-month Treasury bill rates and discount rates - which are closely linked through the term structure of interest rates to the respective monetary policy instruments of the two central banks. During the course of 2001, the South African treasury bill rate edged lower by about 100 basis points, while the three-month treasury bill rate fell by just over 4 percentage points over the same period, reflecting an easing by the Federal Reserve of 450 basis points. Thus, based on information on relative interest rates alone, during this period the SARB policy stance actually tightened relative to the Federal Reserve. A similar result is obtained when the discount rate is considered.

Second, we consider the behavior of monetary aggregates in South Africa. In Figure 8, we plot the growth rates of several monetary aggregates in South Africa and find strong evidence of an acceleration in money growth in 2001. This acceleration could be due to an increase in either money demand or money supply. The latter would be consistent with an expansionary monetary policy stance of the SARB, which would contradict our finding based on the relative interest rate analysis. But if the acceleration in money growth was due to an increase in money demand, then it would not result in a buildup of excess money balances, and there would be little pressure on the exchange rate to depreciate. Such a demand-led expansion in monetary aggregates probably occurred in 1999 when money aggregates also grew rapidly and the exchange rate remained stable (see Figure 8). In 2001, however, the acceleration in money growth was accompanied by a significant exchange rate depreciation and an increase in inflation, which are both strong indications of an acceleration in money supply growth,

Considering that interest rates and monetary aggregates, as indicators of the monetary policy stance, produced contradictory signals in 2001 (whether monetary policy eased significantly or not) it would be useful to estimate a fully specified monetary policy reaction function describing systematic monetary policy in South Africa. A reduction in the short-term interest rate not predicted by the reaction function, for example, could be interpreted as a "surprise" easing of the monetary policy stance, and would give rise to a nominal disturbance. Estimating such a reaction function, however, is complicated by the fact that the monetary policy framework in South Africa has undergone several changes in the last decades, which have led to frequent structural breaks. As a result, estimating a stable and robust policy reaction function has proved to be beyond the scope of this paper. 
Having ruled out real factors as a major factor behind the rand depreciation, and having found contradictory signals regarding changes in the monetary policy stance during this period, this leaves financial market developments as the final promising candidate. For example, it is possible that financial market developments that led to a reduction in the demand for the rand could have caused the depreciation. The Myburgh Commission argued that the rise in global risk aversion toward emerging markets following events in Argentina and Zimbabwe could have had such an effect. As argued earlier, however, the problem with this explanation is again the timing, since the crisis in both countries was well under way before the rand began to depreciate. Thus, the "smoking gun" is still missing.

\section{Conclusion}

The results of our analysis have been summarized in previous sections of this paper, so we will be brief here. Essentially, we find that financial market developments are the most likely source of the depreciation, but the exact cause remains unclear. The Myburgh Commission considered contagion effects and the role of currency speculation, but concluded that these factors alone could not fully explain the depreciation. To identify additional contributing factors, it may be useful to extend the analysis to other financial market variables, because it is unlikely that financial market developments affected only the exchange rate. But this is beyond the scope of the present paper and awaits further research.

Regarding policy implications, a preliminary examination of relative policy interest rates suggests that monetary policy did not contribute directly to the depreciation, but this still leaves open the question of whether the central bank could have been more active in trying to limit the extent of the depreciation. The impulse response analysis shows that, in principle, monetary policy can be very effective with regard to the nominal exchange rate. However, leaning against depreciation would have required a substantial tightening of the monetary policy stance, and it is not clear that this would have been appropriate in an environment of slowing economic growth and muted inflationary pressures. Furthermore, the impulse response analysis shows that the effects of a nominal disturbance on the real exchange rate are fairly short lived, from which it follows that there is less need for strong interventions in the exchange rate market, since the real effects of the depreciation should subside relatively quickly. 
Figure 1. Impulse Response Functions for the Aggregate Supply Shock
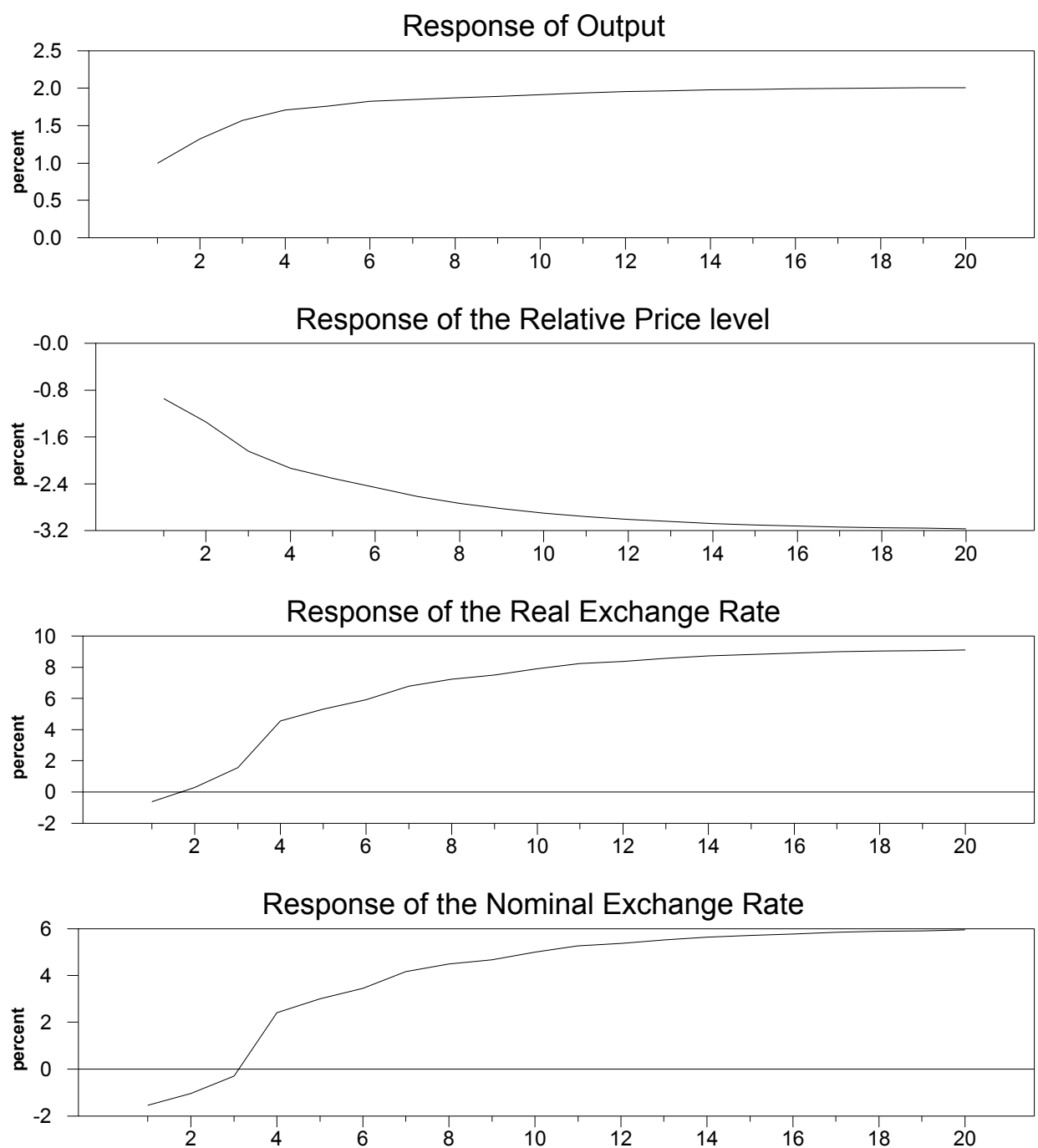

Source: Author's model estimates. 
Figure 2. Impulse Response Functions for the Real Demand Shock
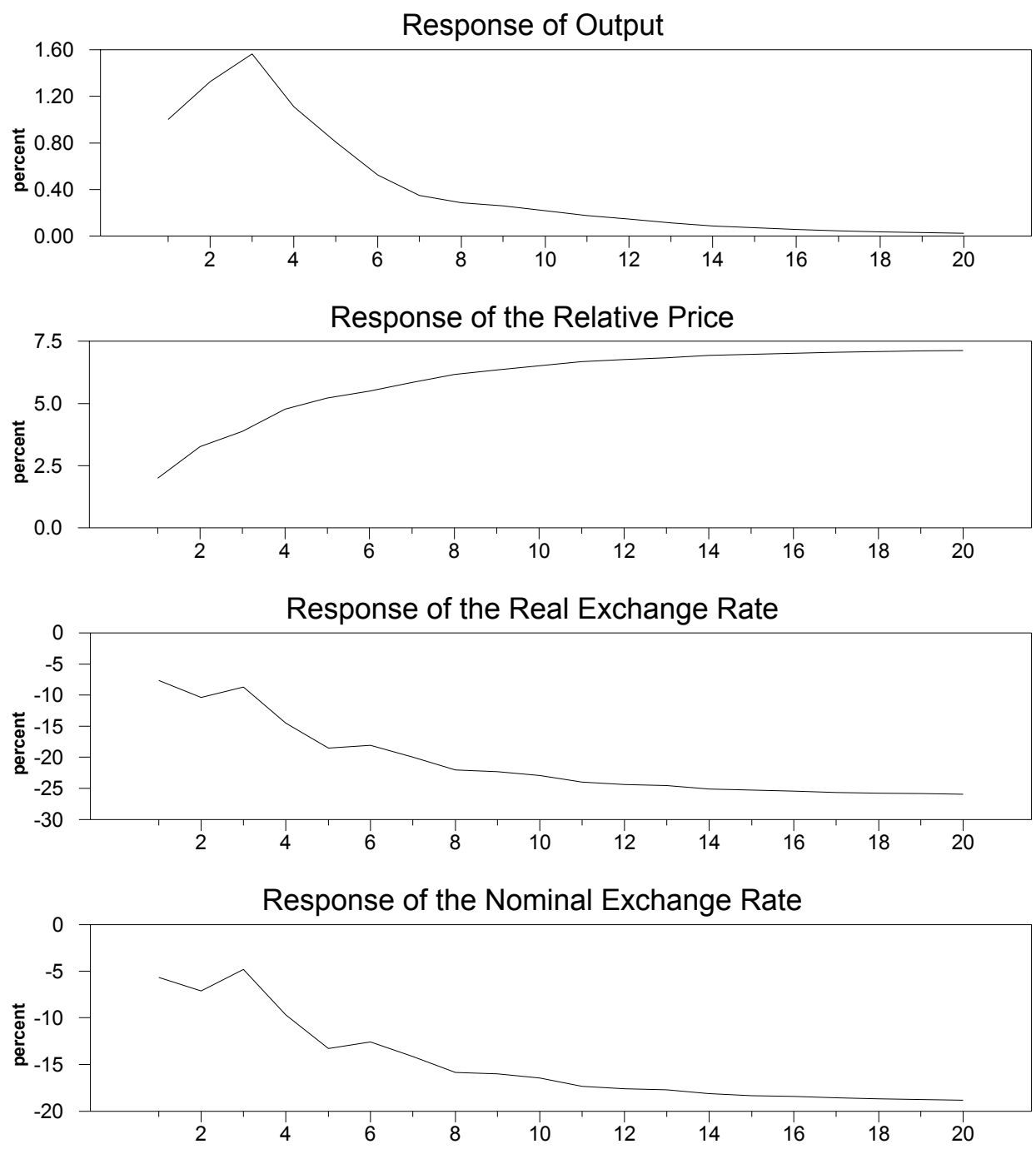

Source: Author's model estimates. 
Figure 3. Impulse Response Functions for the Nominal Shock
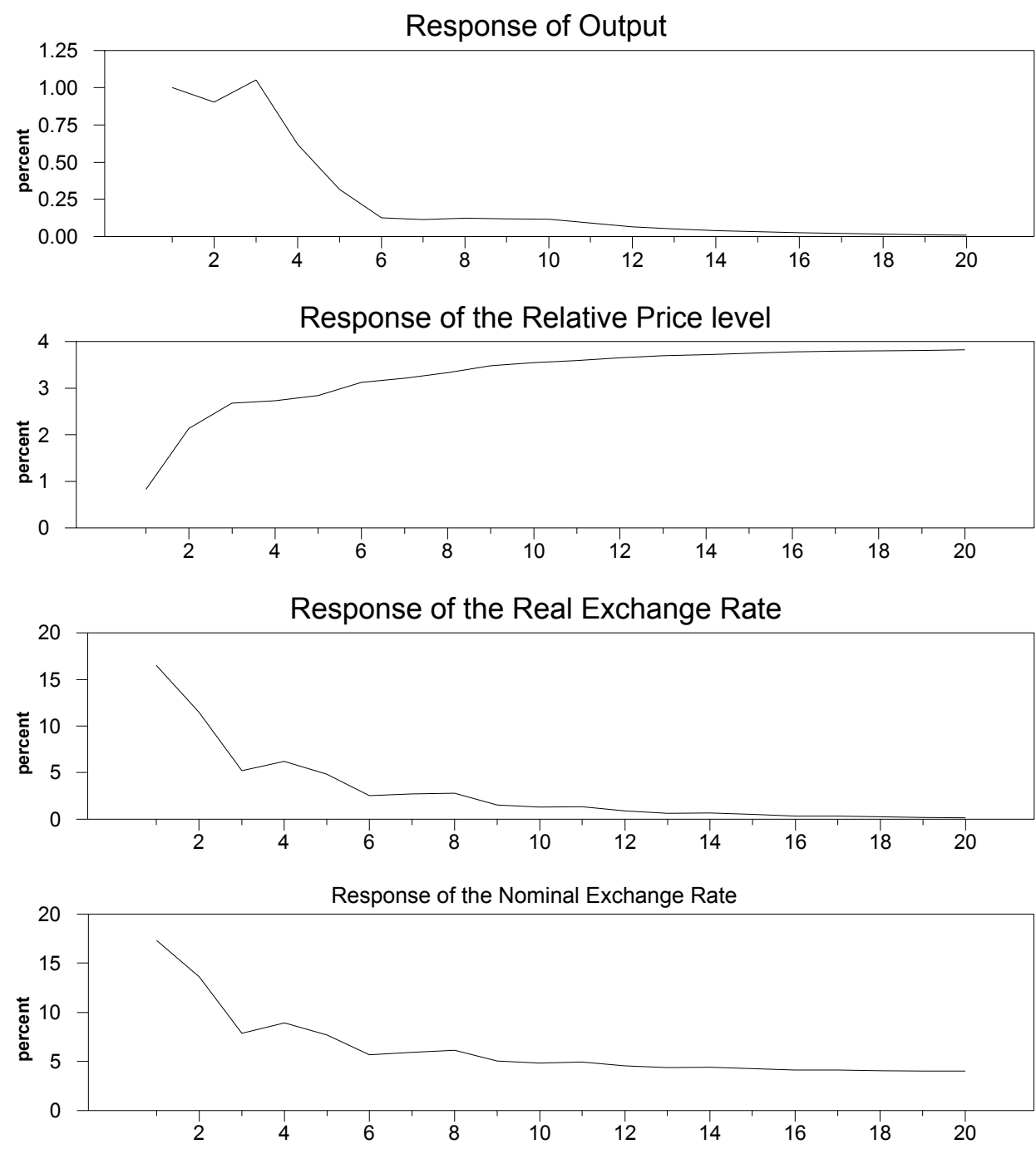

Source: Author's model estimates 
Figure 4. Actual and Projected Annual Change in the Nominal Exchange Rate (In percent)

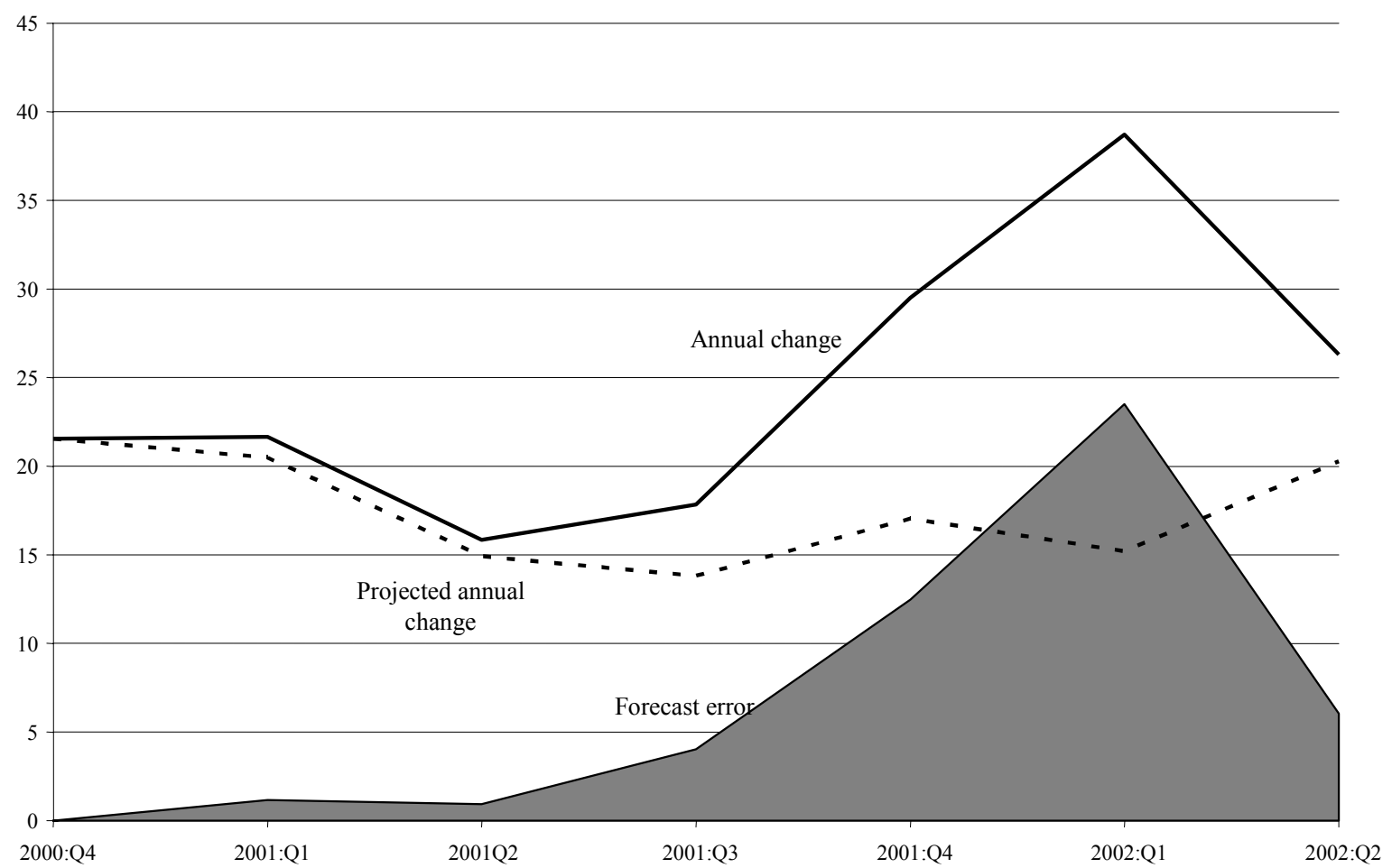

Source: Author's model estimates 
Figure 5. Historical Decomposition of the Nominal Exchange Rate (In percent)
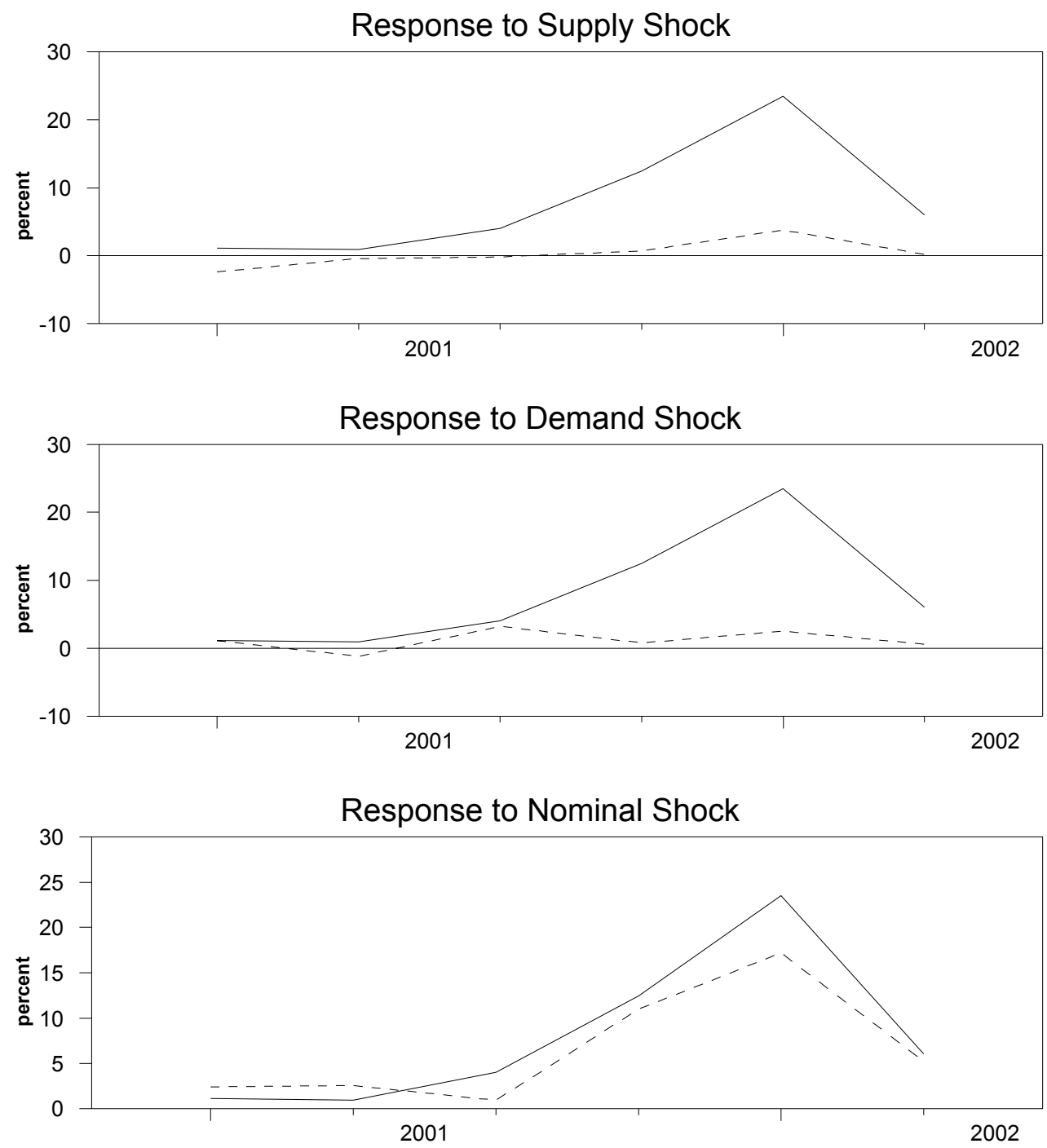

Source: Author's model estimates. 
Figure 6. Nominal Effective Exchange Rates for the Rand and the U.S. Dollar (In percent)

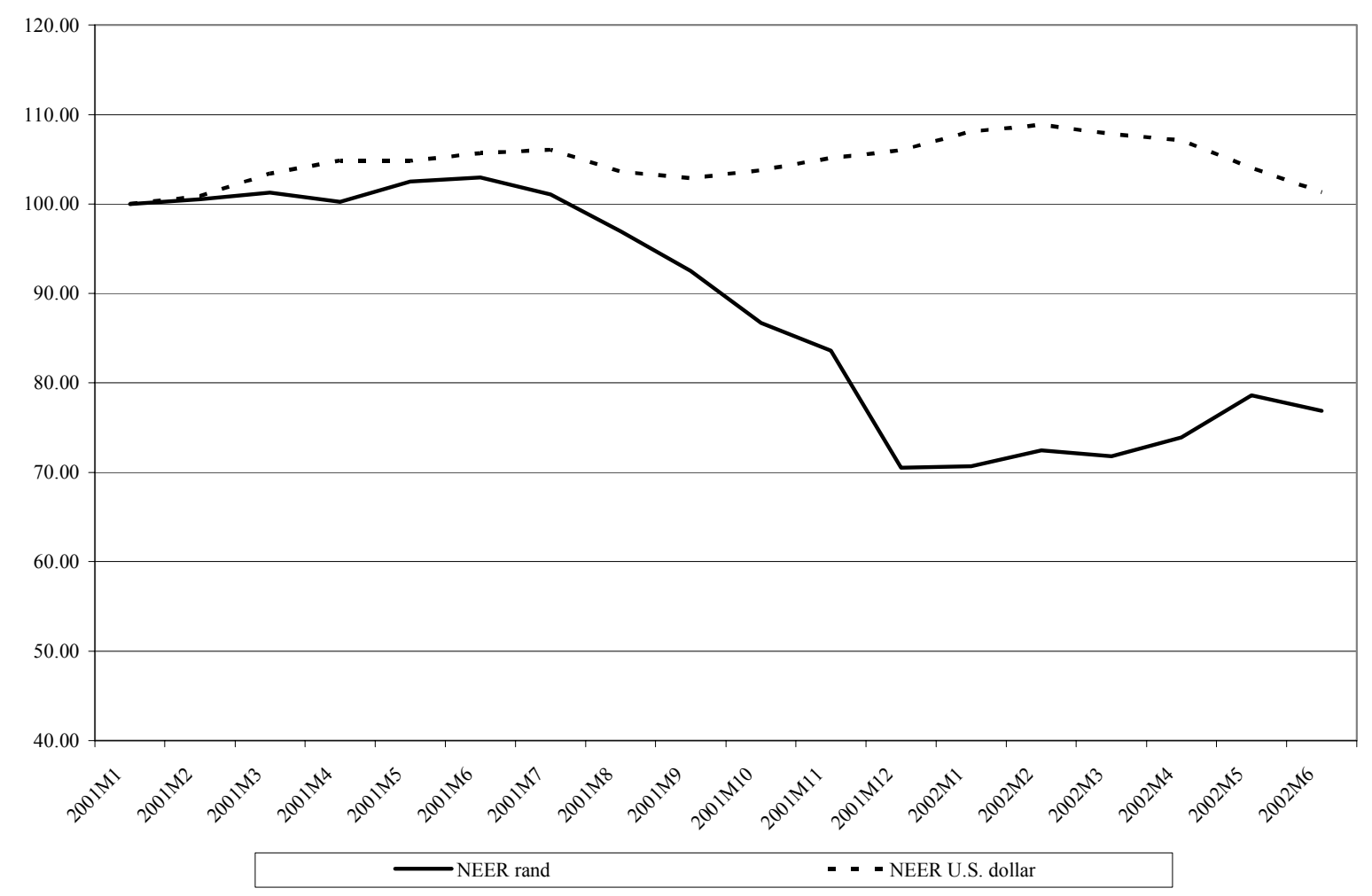

Source: Author's model estimates.

Note: NEER denotes nominal effective exchange rate. 
Figure 7. Relative Monetary Policy Stance in South Africa: Discount Rate and Treasury Bill Rate Differential vis-à-vis the United States

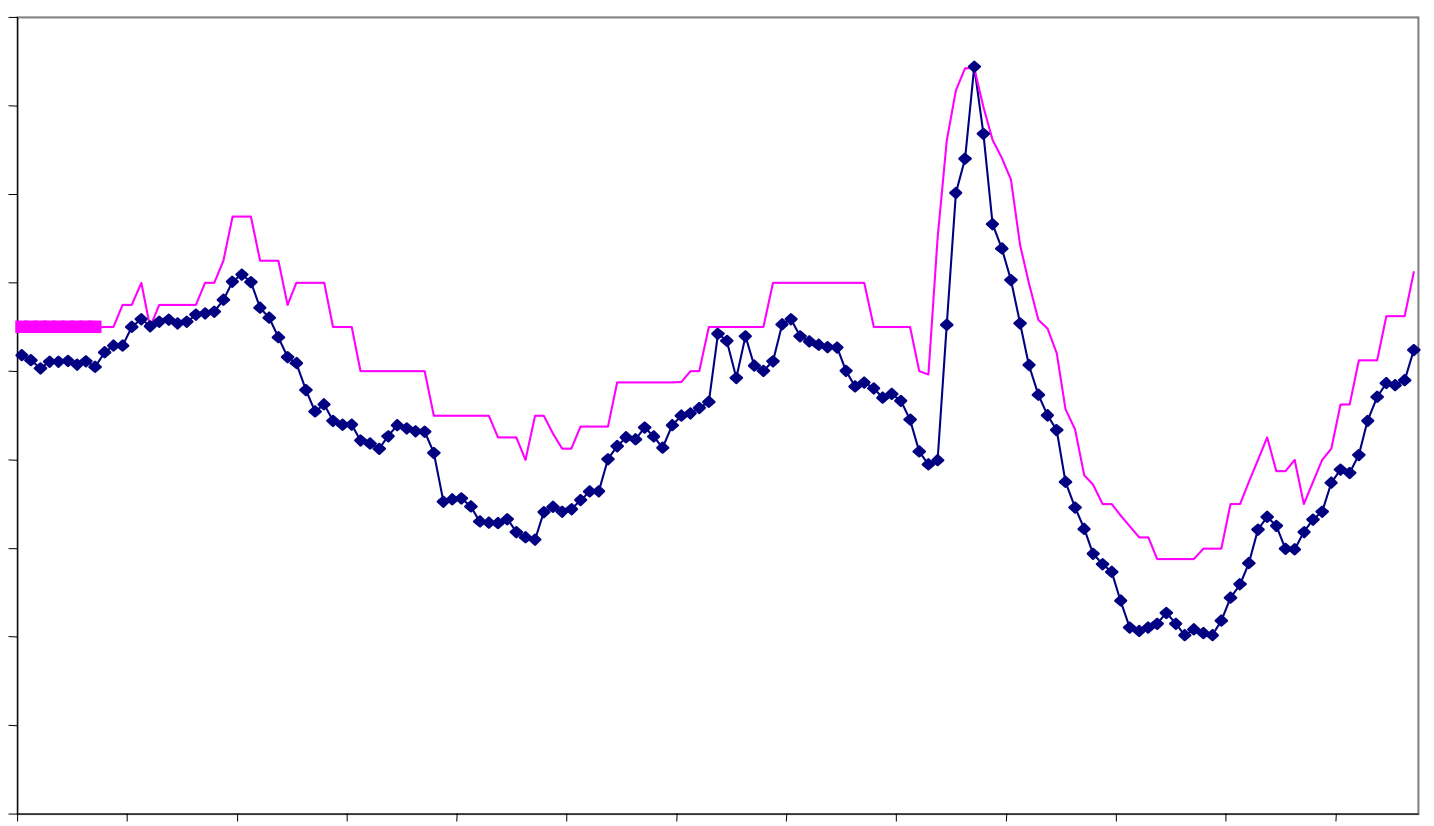

Source: International Financial Statistics. 
Figure 8. Monetary Aggregates and the Rand Exchange Rate (Six-Month Growth Rates in percent)

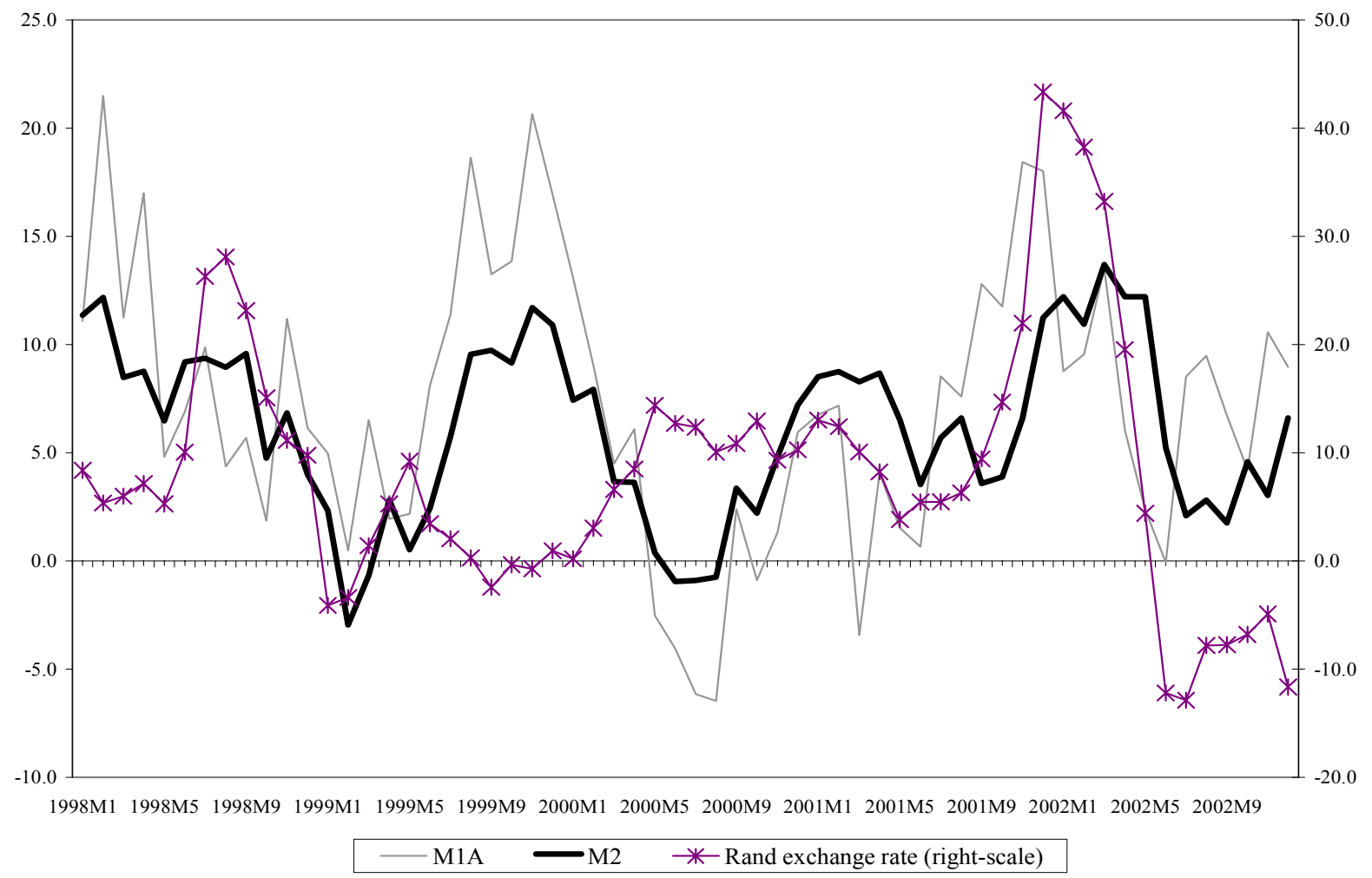

Source: South African Reserve Bank. 
Table 1. Variance Decomposition of the Nominal Exchange Rate

(In Percent)

\begin{tabular}{|c|c|c|c|}
\hline Horizon & Aggregate Supply Shock & Real Demand Shock & Monetary Policy Shock \\
\hline 0 & 3.0 & 9.5 & 87.5 \\
4 & 6.8 & 33.5 & 59.7 \\
8 & 15.5 & 51.4 & 33.1 \\
12 & 20.1 & 58.6 & 21.3 \\
20 & 24.1 & 63.5 & 12.4 \\
40 & 26.7 & 66.3 & 7.0 \\
\hline
\end{tabular}

Source: Author's model estimates. 
Figure A1. Time-Series Plot
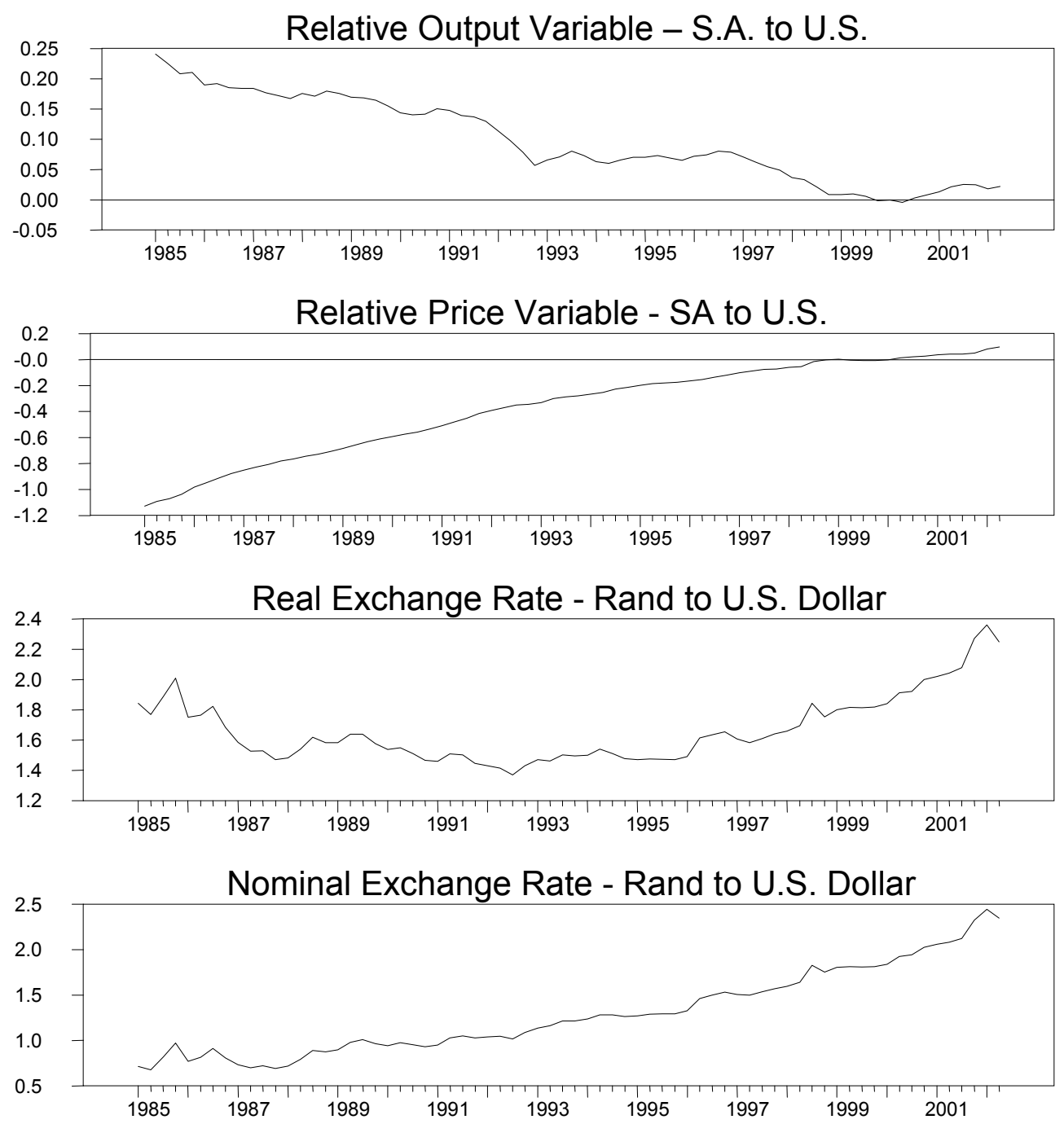

Source: Author's model estimates.

Note: S.A. is South Africa. 
Table A1. Time-Series Properties of Data

\begin{tabular}{|c|c|c|}
\hline Time Series & ADF & Order of integration \\
\hline $\mathrm{y}$ & $-1.98(\mathrm{c}, \mathrm{t})$ & $\mathrm{I}(1)$ \\
$\Delta \mathrm{y}$ & $-6.04^{* * *}(\mathrm{c})$ & $\mathrm{I}(0)$ \\
$p$ & $-2.19(\mathrm{c}, \mathrm{t})$ & $\mathrm{I}(1)$ \\
$\Delta p$ & $-4.91^{* * *}(\mathrm{c})$ & $\mathrm{I}(0)$ \\
$\mathrm{q}$ & $-0.45(\mathrm{c}, \mathrm{t})$ & $\mathrm{I}(1)$ \\
$\Delta \mathrm{q}$ & $-8.01^{* * *}(\mathrm{c})$ & $\mathrm{I}(0)$ \\
\hline
\end{tabular}

Source: Model estimates

Notes: $\Delta$ is the first difference operator. y denotes the relative output variable, $p$ the relative price variable, and q the real exchange rate. The asterisks indicate a rejection of the null hypothesis at the 10 percent $(*)$, the 5 percent $(* *)$, or the 1 percent $(* * *)$ level. The critical values for the ADF test statistics are taken from Hamilton (1994). The brackets indicate the inclusion of a trend ( $\mathrm{t}$ ) and/or a constant (c). The lag length is chosen so that a LM test for serial correlation does not reject the null hypothesis of no serial correlation of order 12.

\section{Table A2. Misspecification Tests}

\begin{tabular}{|l|c|c|c|c|}
\hline \multirow{2}{*}{ Test } & Multivariate & \multicolumn{3}{|c|}{ Univariate Statistics } \\
\cline { 3 - 5 } & Statistics & $\Delta \mathrm{y}$ & $\Delta \mathrm{q}$ & $\Delta p$ \\
\hline AR (1-5) & 1.15 & 0.98 & 0.49 & $3.05^{*}$ \\
Jarque-Bera & 7.61 & 3.07 & 1.93 & 1.64 \\
ARCH (4) & & 0.58 & 0.18 & 2.20 \\
White & \multirow{2}{*}{1.00} & $2.13^{*}$ & 0.46 & 1.44 \\
\hline Hansen & & 1.91 & 2.38 & 2.23 \\
\hline
\end{tabular}

Source: Model estimates

Notes: The asterisks indicate a rejection of the null hypothesis at the 10 percent $(*)$, the 5 percent $(* *)$, or the 1 percent (***) level. The AR (1-5) statistic gives the result of a LM-test for autocorrelated residuals up to order 5. For single equations this test statistic has a $\mathrm{F}(5,51)$ distribution, in the multivariate case it is $\mathrm{F}(45,116)$. Jarque-Bera is the conventional Jarque-Bera test for normality test. ARCH 4 is a LM test for autocorrelated squared residuals of order 4 with a $\mathrm{F}(4,48)$ distribution. The White statistic is the test statistic of a test for heteroscedasticity. The respective distributions are $\mathrm{F}(18,37)$ and $\mathrm{F}(108,190)$. Hansen is a stability test based on Hansen (1992); the critical values at the 5 percent and the 1 percent level are 3.15 and 3.69. 


\section{REFERENCES}

Astley, Mark, and Anthony Garratt, 2000, "Exchange Rates and Prices: Sources of Sterling Real Exchange Rate Fluctuations," Oxford Bulletin of Economics and Statistics, Vol. 62, No. 4, pp. 491-509

Bernanke, Ben S., 1986, "Alternative Explanations of the Money-Income Correlation," Carnegie-Rochester Conference Series on Public Policy, Vol. 25, pp. 49-100.

Blanchard, Olivier, and Danny Quah, 1989, “The Dynamic Effects of Aggregate Supply and Demand Disturbances," American Economic Review, Vol. 79, pp. 655-73.

Clarida, Richard, and Jordi Gali, 1994, "Sources of Real Exchange Rate Fluctuations: How Important Are Nominal Shocks?," Carnegie-Rochester Conference Series on Public Policy, Vol. 41, pp. 1-56.

Dornbusch, Rudiger, 1976, "Expectations and Exchange Rate Dynamics," Journal of Political Economy, Vol. 84, pp. 1161-76.

Fackler, James S., and W. Douglas MacMillin, 1997, "Historical Decomposition of Aggregate Demand and Supply Shocks in a Small Macro Model," Southern Economic Journal, Vol. 64, pp. 648-664.

Funke, Michael, 2000, "Macroeconomic Shocks in Euroland vs. the UK: Supply, Demand, or Nominal?," European University Institute Working Paper No. RSC2000/37

Hansen, Bruce E., 1992, “Testing for Parameter Instability in Linear Models," Journal of Policy Modeling, Vol. 14, pp. 517-33.

Johansen, Soren, 1988, "Statistical Analysis of Cointegration Vectors," Journal of Economic Dynamics and Control, Vol. 12, pp. 231-54.

Lane, Phillip, 2001, “The New Open Economy Macroeconomics: A Survey,” Journal of International Economics, Vol. 54, pp.235-66.

Myburgh, 2002, Final Report of the Commission of Inquiry into the Rapid Depreciation of the Rand and Related Matters. Available at http://www.gov.za/bodies/myburgh/. 